Iowa FACE Report:

Case ID:

Date:

\section{Farm worker electrocuted while pressure-washing interior of swine barn}

2008 IA 074

5 December 2014

\title{
Summary
}

In fall of 2008, a 34-year-old Hispanic man was electrocuted while using a pressure washer to clean the interior of a swine finishing barn. ${ }^{1}$ He and a coworker had been assigned to pressure wash buildings at local farms managed by their employer.

The victim was a native of Honduras who had worked in the US for several months before moving to the local area. The incident occurred on his sixth day of work.

The day of the fatality, the victim and his coworker arrived to work at the farm where the incident later occurred. Their supervisor, the site manager, instructed them to clean the finishing barn's concrete floors and steel gate partitions using the electric-powered high pressure washer they had used in other buildings that week.

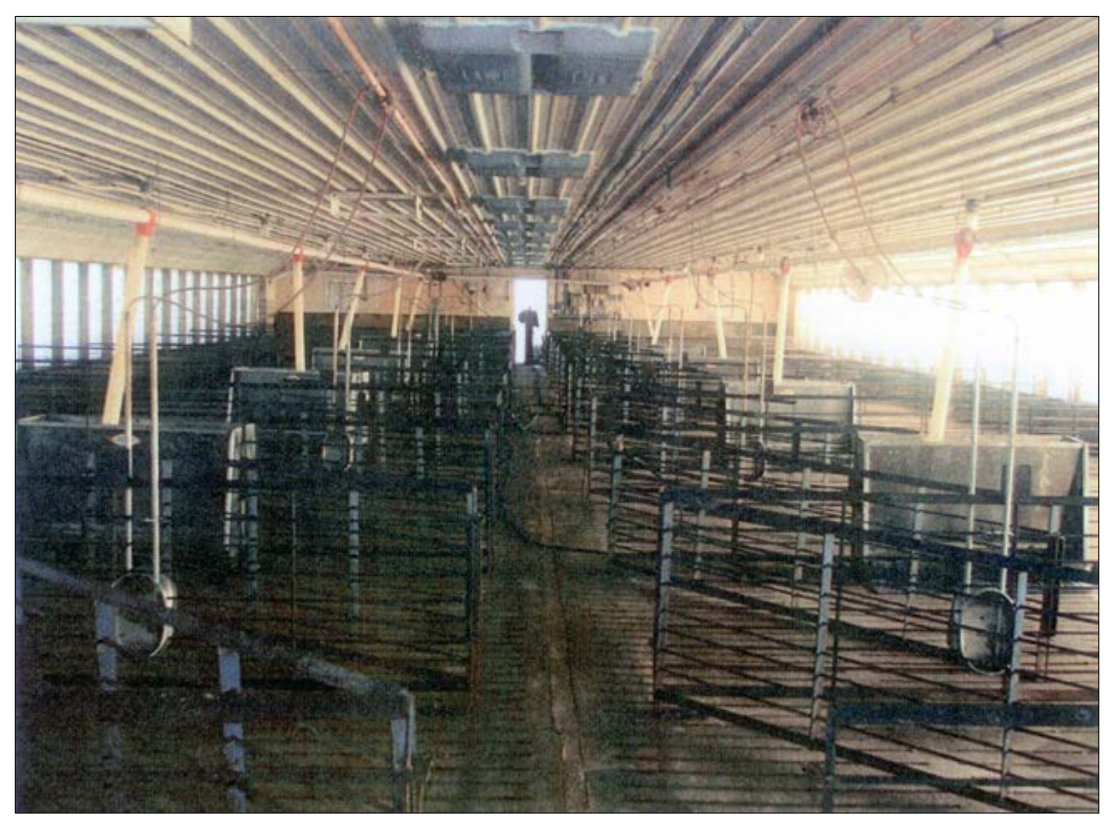

At mid-morning, the coworker left to work at a different farm, but he returned to eat lunch with the victim over the noon hour. During lunch, the two workers discussed that the washer continued to malfunction just as it had during the week. After lunch, the coworker went back to the farm where he had been working, and the victim resumed pressure washing alone. The site manager returned to the barn at 15:30 to check on the victim's progress and saw him inside, slumped over a steel gate partition along the center aisle of the main room.

The manager tried to rouse the unresponsive victim and pulled him to the loading dock area adjacent to the main room. The victim was cold and without a pulse. The manager called 911, and he then disconnected power at the circuit breaker and turned off the faucet supplying water to the pressure washer. Within several minutes, the county Sheriff, an ambulance crew, and local emergency responders arrived from a town nearby. The county Medical Examiner arrived at the site and pronounced the victim dead at 16:00.

The position of the victim's body when found suggested that he had been leaning over the gate to reach the pressure washer. An autopsy identified an electrical burn injury to the victim's right thigh where it had contacted the steel gate. The cause of death was determined to be electrocution.

1 A building used to house and feed hogs for approximately 3-4 months, from feeder pig weight (40-50 lb.) to market weight (220-270 lb.) 
Law enforcement agencies and the Iowa Division of Labor Services/Occupational Safety and Health Bureau (IOSHA) investigated the fatality. Interviews with the victim's manager and coworker revealed that the pressure washer had a history of electric malfunction that was known to the manager and employees for several days preceding the fatality: workers who handled the metal wand or high pressure hose had received electric shocks; the machine "threw sparks" when its metal wand contacted other metal surfaces in the buildings; power surges of the pressure washer motor caused room lights on the same circuit to dim; and the machine periodically shut off while in operation. Four days before the fatality, it had short-circuited, tripping circuit breakers and burning a receptacle at a different farm building.

The pressure washer was taken to a local dealership for inspection by the manufacturer's product engineers and the IOSHA compliance officer. They found evidence of water in the metal electrical panel box that had caused extensive corrosion. Inside the electrical panel box, there was thermal damage to conductor insulation and electrical components caused by current overload. Damage to conductor insulation created a situation wherein 1) the exposed hot and neutral conductors could contact each other, creating a short circuit, and 2) the exposed conductors could contact the interior surface of the electrical panel box, creating a fault that energized the panel box and all connected metal parts of the pressure washer, including the frame, wand, and exposed braiding on the high pressure hose.

The pressure washer model involved in this incident was not certified to the UL 1776 voluntary pressure washer safety standard which specifies a number of safety features designed to protect the operator, including built-in ground fault circuit interrupter ${ }^{2}$ (GFCI) protection. The pressure washer and the building installation both lacked GFCI devices designed to open the circuit upon detection of low levels of current flowing along an unintended path.

When the victim touched a metal surface of the energized pressure washer at the same time his body was in contact with the steel gate, his body became part of the fault current path to ground.

Factors contributing to this incident include:

- use of equipment with a known history of electrical malfunction that was not maintained in safe operating condition

- use of electrical equipment without GFCI protection

- $\quad$ workers were not provided training in operation and safety hazards of electrical equipment

To prevent future incidents of this nature Iowa FACE recommends that employers:

- $\quad$ use pressure washers only in applications where ground fault circuit interrupter (GFCI) protection is present and in working order

- $\quad$ maintain pressure washers in proper operating condition; remove malfunctioning equipment from service until repairs have been made by qualified repair personnel

- $\quad$ train workers on electrical hazards associated with operating pressure washers, including risks for electric shock, routine inspection and maintenance, and proper use of equipment; verbal training and written materials should be provided in workers' primary language

\section{Introduction}

A 34-year-old Hispanic worker was electrocuted while pressure washing the interior of a swine barn in 2008. Law enforcement agencies began an investigation of this death the day of the fatality, and IOSHA began an investigation the following day. Iowa FACE learned of the incident through the media and began a preliminary investigation three days after the fatality. An indepth FACE investigation was initiated in 2012. Telephone interviews were conducted with the county Medical Examiner and a law enforcement agent (both of whom responded at the scene); the owner of the building where the incident occurred; and the principal of the corporate farm that contracted with the victim's employer to manage livestock operations. A request to visit the site was declined. The victim's employer was no longer in business at the time of the FACE in-depth investigation.

This report was prepared utilizing information obtained from telephone interviews, law enforcement agencies' investigative reports, the county Medical Examiner and Iowa Office of the State Medical Examiner case reports, the IOSHA case file, and county assessor property records. The photographs included in this report are attributed to the Iowa Division of Criminal Investigation (DCI), the county Sheriff's Office, and IOSHA.

\footnotetext{
2 also referred to as ground fault interrupter (GFI) or residual current device (RCD)
} 


\section{Employer}

Three separate business entities are mentioned in this report. They include:

Employer: The victim's employer was a private corporation providing management, consulting, and labor services for swine production to several large farm operations over a large geographic area. The employer's business office was located 140 miles from the farm where the fatality occurred. Per IOSHA's case file, the employer's workforce consisted of 13-18 individuals, including the site manager and an area production manager mentioned in this report. The site manager and the area manager had been employed for periods of three months and one year, respectively. The site manager oversaw three local farm sites, including the farm where the fatality occurred. The employer's hourly laborers were moved on an as-needed basis between several livestock operations in regional areas. Several of their laborers were Hispanic workers whose primary language was Spanish. Employees were not affiliated with an organized labor union.

Corporate farm/lessee: A corporate farm owned the livestock that were kept at the incident site and two other farm sites, which together had a total capacity of 10,000 head. The corporate farm leased the property where the incident occurred and contracted with the victim's employer for labor and related services involving care of hogs at the sites.

Property owner/lessor: This individual owned the land and buildings where the incident occurred. He was not involved in the livestock production or management of workers at the site.

\section{Written safety programs and training}

IOSHA noted that the employer had no safety and health programs, written safety policies, or employee training programs in workplace health and safety. The employer had not performed hazard assessments of the facilities where employees worked and did not have a hazard communication program.

\section{Victim}

The decedent was a native of Honduras whose wife and children resided there. He was an undocumented laborer who had come to the US eight months earlier to find employment. He had worked in Kentucky before coming to Iowa to live with his Honduran friend (the coworker) one and a half months earlier. His friend had worked for the employer at livestock farms in another area of the state, and he had suggested the victim could get hired on as well.

The victim was hired the week preceding the fatality, and an area manager assigned the victim and coworker to clean buildings at three farms in a different region. The coworker and victim drove 140 miles to the area where the farms were located and were put up in a motel at a nearby town. They worked under the direction of the site manager, and their main assignment was pressure washing the interior of barns that were empty after pigs were loaded out. They were scheduled to work 11- to 12hour days, six days per week. They were paid $\$ 9$ per hour with the cost of their motel room deducted from their wages. The fatality occurred on the victim's sixth day of work.

The primary language of the victim and his friend was Spanish. ${ }^{3}$ The IOSHA report noted the victim spoke English "not at all." The site manager - who spoke only English - told investigators that the two "couldn't understand English." Other bilingual Hispanic employees assisted with communication.

\section{Weather/environment}

The incident occurred indoors in an unheated livestock building. The outdoor temperature was approximately $28^{\circ} \mathrm{F}$. Weather was not a factor in this incident.

The activity of pressure washing resulted in damp conditions and wet surfaces inside the building, including the victim's wet clothing and skin. These conditions increase the severity of electric shock injury.

\footnotetext{
${ }^{3}$ Interpreters and translators were used during investigation interviews with the victim's Honduran coworker.
} 


\section{Incident scene}

The fatality occurred at a 2.8-acre rural property located three miles from a small town and seven miles from a municipality with a hospital and the motel where the workers lived. The acreage was used solely for livestock production. Structures on the property included a "pole frame" utility building, two steel bulk feed tanks, and the swine finishing barn, all of which were built in 1993.

The $248^{\prime} \times 41^{\prime}$ barn was constructed of wood framing with metal siding and roof. Its length was oriented east/west, and it had ventilation curtains along the long north and south walls. A partially-enclosed $12^{\prime} \times 20^{\prime}$ loading dock was built onto the east end of the building. The interior of the building was open with a slatted cement floor over an $8^{\prime}$-deep manure storage pit. Steel gate partitions approximately $3^{\prime}$ high divided the interior area into individual pens and a center aisle spanning the length of the building. (Exhibit $A$ )

The property owner had the building's ventilation system upgraded "shortly before the fatality." The work was done by a livestock equipment vendor and a local electrical firm licensed for commercial work. The upgrades involved adding new fans, shutters, fresh air inlets, and a computerized ventilation control system. The owner noted that the upgrades did not require changes to the building's electrical service.
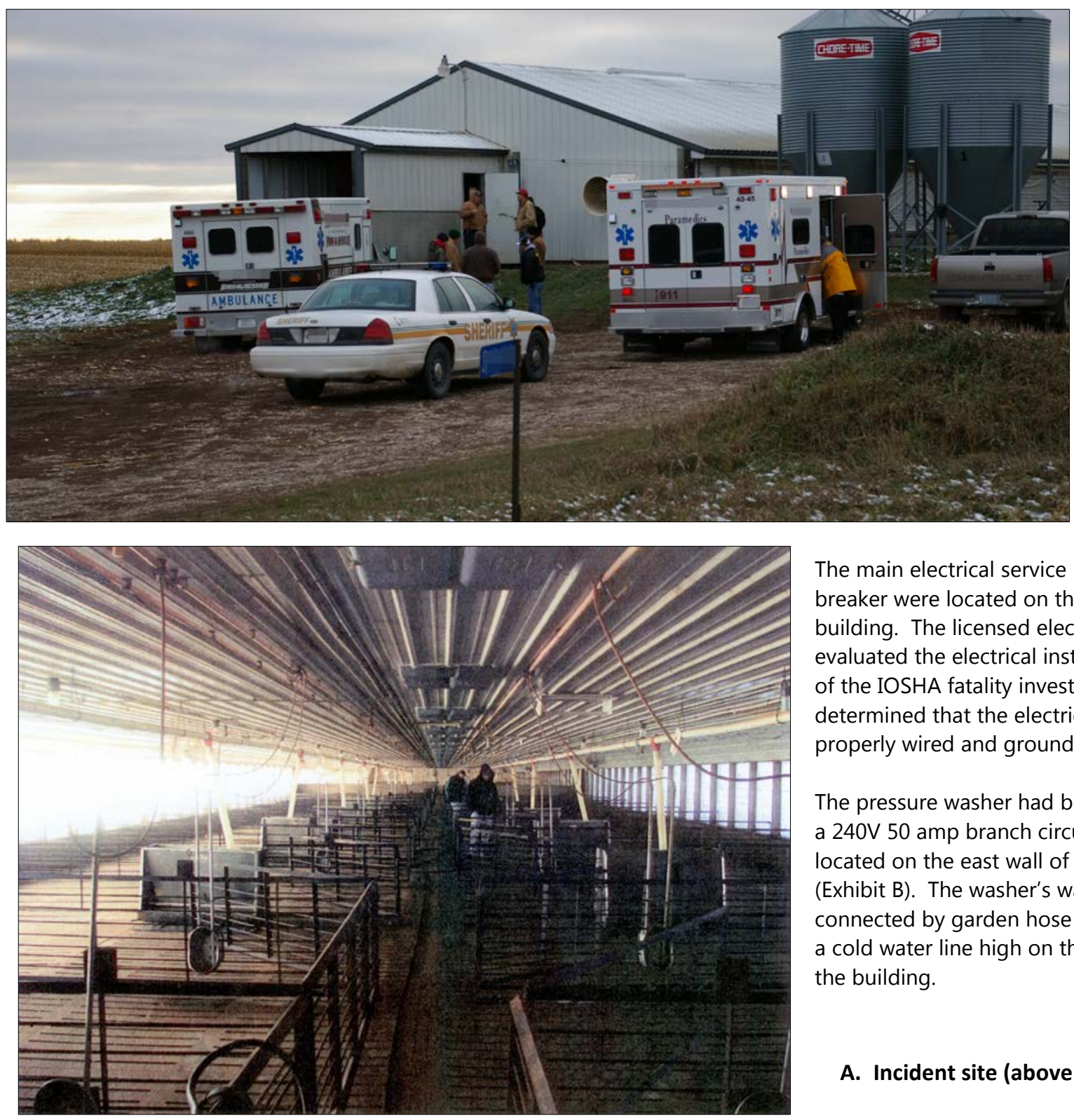

The main electrical service panel and breaker were located on the exterior of the building. The licensed electrician who evaluated the electrical installation as part of the IOSHA fatality investigation determined that the electrical circuits were properly wired and grounded.

The pressure washer had been plugged into a $240 \mathrm{~V} 50 \mathrm{amp}$ branch circuit receptacle located on the east wall of the building (Exhibit B). The washer's water inlet was connected by garden hose to the faucet of a cold water line high on the east wall of the building.

\section{A. Incident site (above and left)}




\section{Equipment}

The victim had been using an electric-powered Alkota model HHS 532 cold water high pressure washer (Exhibit B). ${ }^{4}$ The HHS (Hog House Special) series washers were not certified to the UL 1776 pressure washer safety standard.

The washer was manufactured and inspected in January 2004 and shipped to a local industrial equipment wholesale and service dealership in February. It was purchased new with accessories in 2004 by a livestock producer who previously had leased the farm where the fatality occurred. This producer later went out of business and left the washer at the farm, where it was on loan to the victim's employer.

The washer's safety and instruction decals were printed in English (Exhibit C).

The operator manual includes the following steps to operate the equipment:

\section{Start-up}

1. Connect the power cord to an electrically grounded circuit that is fuse or circuit breaker protected. If the correct type of receptacle is not available, have one installed by a qualified electrician.

2. This machine must have a water supply meeting or exceeding the maximum discharge volume specified in the machine specification, and a minimum water inlet pressure of 40 PSI.

3. Gun assembly in hand: (on trigger gun models hold the trigger gun valve in open position) and with a good flow of water turn the switch to pump position. Caution: a good flow of water must be flowing from the end of a gun for 30 seconds before proceeding. Lack of water can cause damage to the water pump and like components. Caution: On a machine equipped with a trigger gun valve, if the trigger gun valve remains in the closed position for more than 3 minutes, water pump damage may occur.

\section{Shut-down}

1. Turn the pump switch to the off position.

2. Turn off the water supply.

\footnotetext{
4 HHS 532 equipment specifications

S/N: 225816

Size: $28.5^{\prime \prime}$ L x 19.5" W x 45" H; 310 lbs.
}

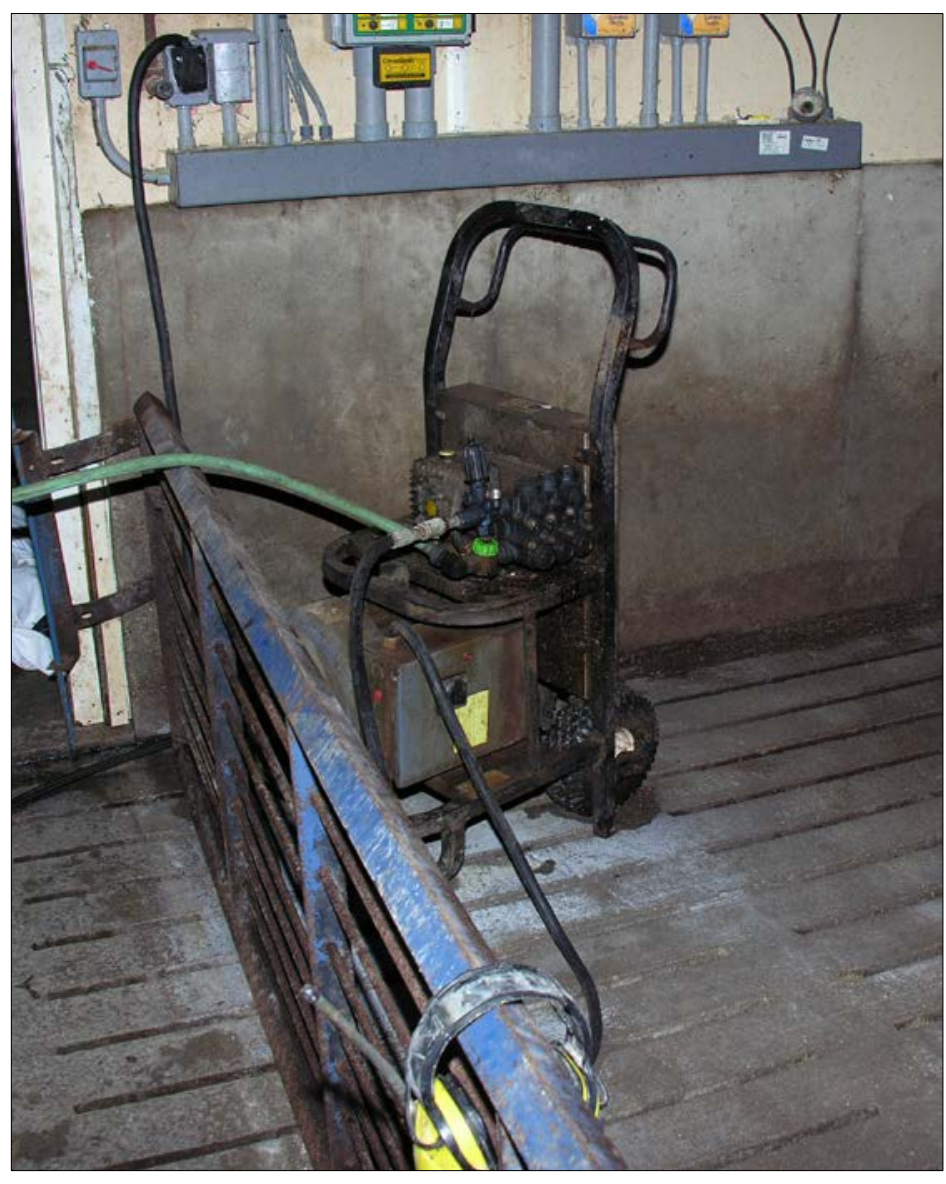

B. Pressure washer plugged into wall receptacle at site

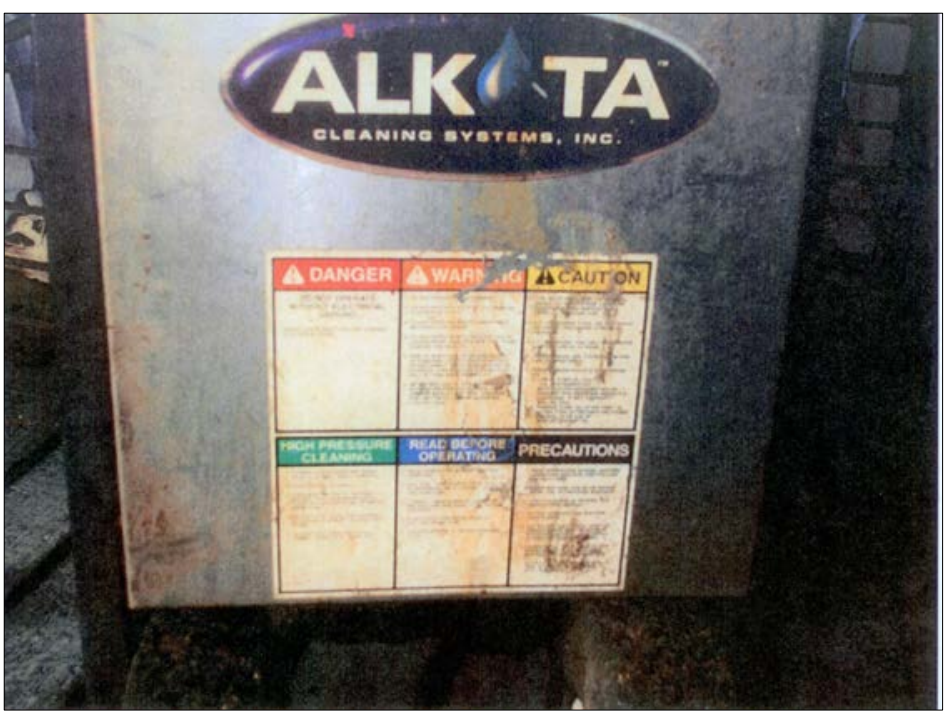

\section{Warning labels}

Motor: $10 \mathrm{HP} 230 \mathrm{~V} 1 \mathrm{PH} 39$ amps

Pump: 3000 PSI, 5.0 GPM discharge volume 
The dealership's service records indicated that the owner had purchased a nozzle and a switch for the washer the year preceding the fatality. Eight months before the fatality, the owner had contacted the dealer to purchase a new cover for the electrical panel box, because 'someone had taken the electric box cover off.' Dealership records showed the new cover for the electrical panel had been returned seven months before the fatality.

Alternations had been made to the equipment (from original configuration) that were not performed by the dealer's service department. These included:

- $\quad$ several sections of high-pressure hose had been coupled together to a total length of approximately 200'

- the water inlet had been rotated 180 degrees, resulting in the hose attachment being oriented directly above the electrical panel (Exhibit D)

- $\quad$ the electrical panel cover had been attached in an inverted (upside down) orientation (Exhibit E)

- $\quad$ the original cord set plug had been replaced with an appliance plug; ${ }^{5}$ electrical tape was wrapped around the cord to close the opening where the cord entered the replacement plug (Exhibit F)
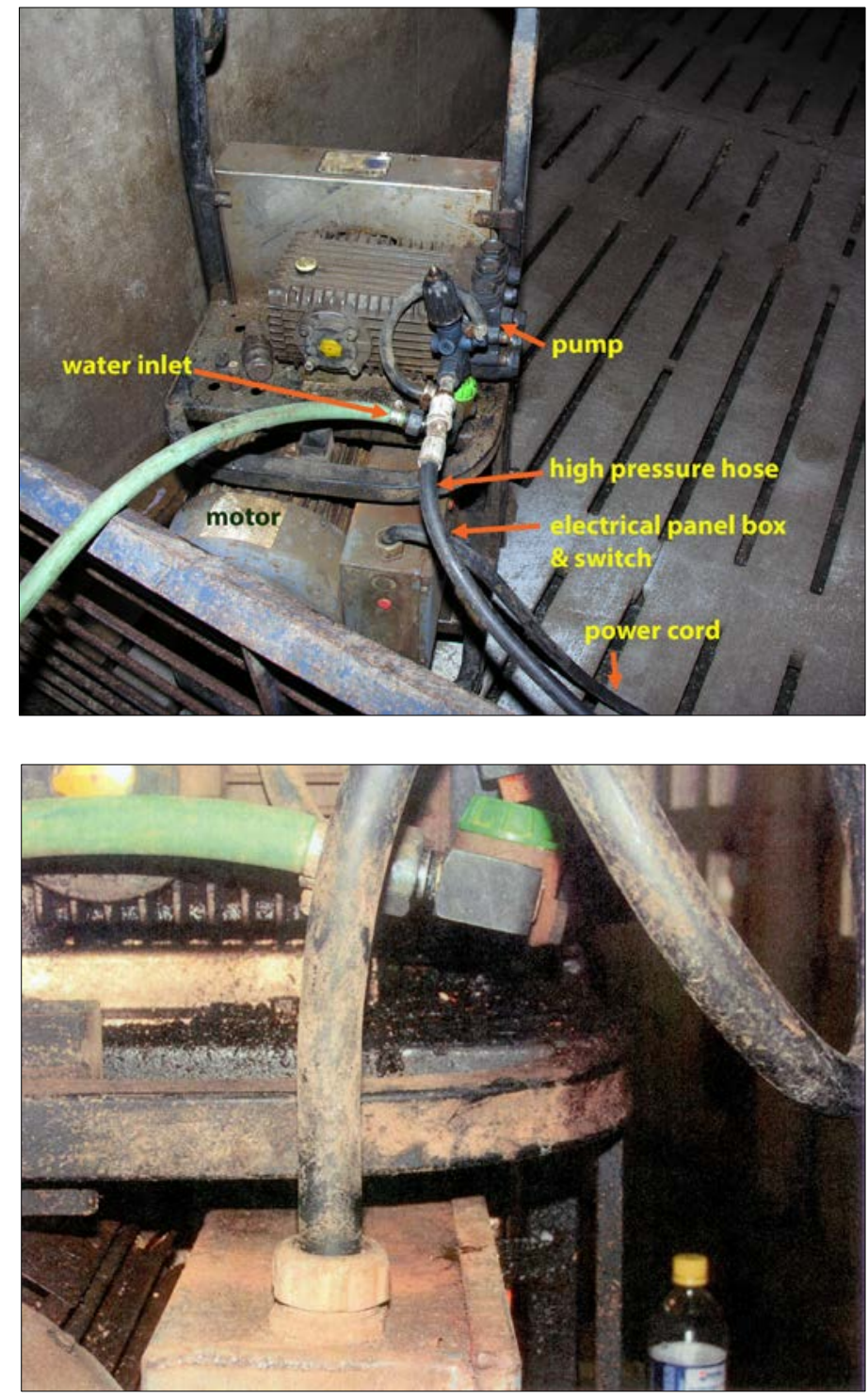

\section{Water inlet located above electrical panel box (2 photos above)}

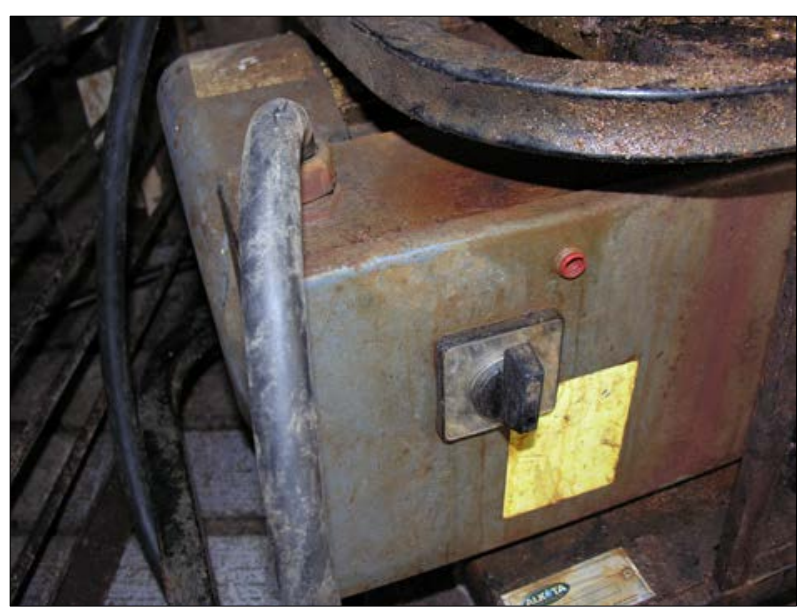

\section{E. Cover of electrical panel box replaced in inverted orientation (above)}

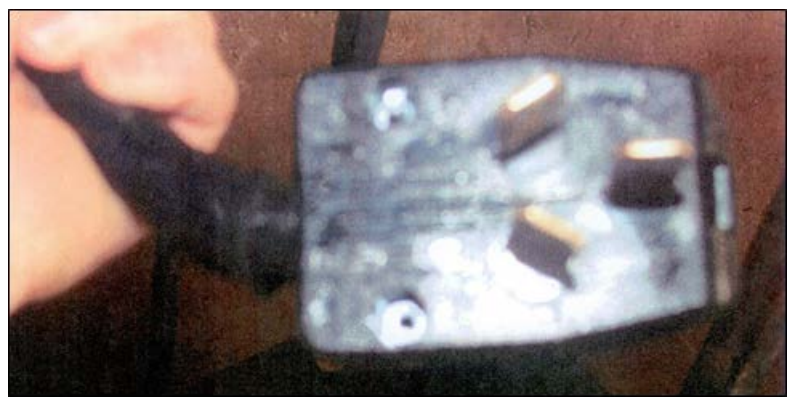

\section{F. Replacement plug at end of pressure washer power cord}

\footnotetext{
5 The original plug was a NEMA 6-50 configuration; the replacement plug was a NEMA 10-50 configuration.
} 


\section{Investigation}

The victim and his coworker drove to their newly assigned work region on the Monday preceding the fatality. They worked under the site manager's supervision Tuesday through Saturday, pressure washing barns at a farm nearby. During the week, there were indications that the pressure washer was malfunctioning: it had shocked workers, shut off intermittently, and caused room lights to dim. On Wednesday, it had short circuited, tripping circuit breakers and burning a receptacle. After this occurred, the manager replaced the plug on the cordset. On Saturday, the washer was transported by truck to the incident site. The interior of the empty barn had to be washed down before new pigs arrived on Monday.

On Sunday morning, the victim and his coworker ate breakfast at their motel and rode in the coworker's car to the farm, arriving around 07:00. The site manager told them to get started pressure washing and then left to go to another farm. He checked on the workers at 08:30 and then returned again around 10:30 to assign the coworker to feed and vaccinate pigs at another farm. The manager and coworker departed for this farm, leaving the victim alone to pressure wash.

Around 12:15, the coworker returned to the first site to eat lunch with the victim. During their lunch break, the two coworkers discussed that the washer hose was still shocking them unless they unplugged or shut off the machine prior to moving the hose. The site manager observed the two eating when he stopped by the farm. At around 12:30 or 13:00, the coworker returned to the farm where he had been working, and the victim resumed pressure washing.

When the site manager returned to farm at 15:30 to check the victim's progress, he did not hear the pressure washer running. He opened the door between the loading dock and main room and saw the victim slumped over a center aisle partition near the pressure washer, with his knees bent and his arms hanging down. The manager tried to rouse him but was unsuccessful. He grasped the victim under the arms and pulled him through the east doorway to the loading dock. The manager was unable to detect a pulse. He drove his truck to the corner to get the rural address location and called 911 at 15:41. He described the victim as "purple" and "cold," and stated he could not open the victim's mouth to perform CPR.

While waiting for emergency responders to arrive, the manager shut off power to the circuit at the breaker and turned off the water faucet where the garden hose was connected.. He noted at that time that no breakers had been tripped, and that the power to the building was still on.

Within several minutes of the call, emergency personnel, an ambulance, and the county Sheriff arrived from the town seven miles away. Emergency responders took over caring for the victim, but he did not regain consciousness. The Sheriff

summoned the county Medical Examiner and a DCI law enforcement agent to the scene. The site manager went to retrieve the victim's coworker from the farm where he had been working. The Medical Examiner pronounced the victim dead at 16:00.

The scene inside the building is shown in Exhibit G. When the victim was discovered, the washer's power cord was plugged into a receptacle on the east wall and the power switch was in the "off" position. The garden hose connected to the pressure washer's water inlet was strung across the center aisle gates and attached to a faucet on the east wall. A long length of high pressure hose connected to the washer was strung along the floor and draped over the steel partition gates in the east half of the building. Another section of high pressure hose was connected to the trigger gun and wand that rested on a center aisle gate in the middle of the building. The victim's earmuffs were resting on top of the metal gate near his body. The east half of the building had been cleaned.

The victim was clothed in a nylon jacket over coveralls, denim jeans, and a short sleeved shirt. He was wearing rubber boots and "work gloves" of unspecified type. His gloves, clothing, and skin were wet. His outer clothing and gloves were dirty with manure stains. There were horizontal burn marks on the victim's coveralls and jeans at the right upper thigh near the groin area. The victim's fists were clenched and his arms were slightly flexed.

The incident was not witnessed, but evidence at the scene suggested that the victim may have uncoupled sections of the high pressure hose in the center of the room and set the wand on the gate before walking to the east end of the building to turn the pressure washer off. It is speculated that he may have turned the pressure washer off either in preparation to move it to the west half of the building to continue cleaning or as part of the resetting procedure in the event that the motor's thermal overload switch had tripped. ${ }^{6}$ The position of the victim's body and location of the electrical burn suggests that in the process of turning off the washer, he touched the energized metal electrical panel or the frame of the washer while leaning against the steel gate.

\footnotetext{
6 This procedure is described in a trouble-shooting section of the equipment operator manual.
} 
Law enforcement agents and the county Medical Examiner interviewed the site manager and the victim's coworker (the latter using the assistance of a bilingual interpreter). IOSHA initiated an investigation the following morning. Interviews with the site manager and coworker confirmed that the pressure washer had malfunctioned throughout the week while it was used at a different farm: it had shut off while in use, shocked workers who handled the hose, threw sparks when the metal wand contacted other metal surfaces, and tripped circuit breakers. On the day of the fatality, the washer motor had run erratically (i.e., sped up and slowed down), and the coworker and victim had received shocks when they moved the high pressure hose or touched the metal connector between the gun and hose.
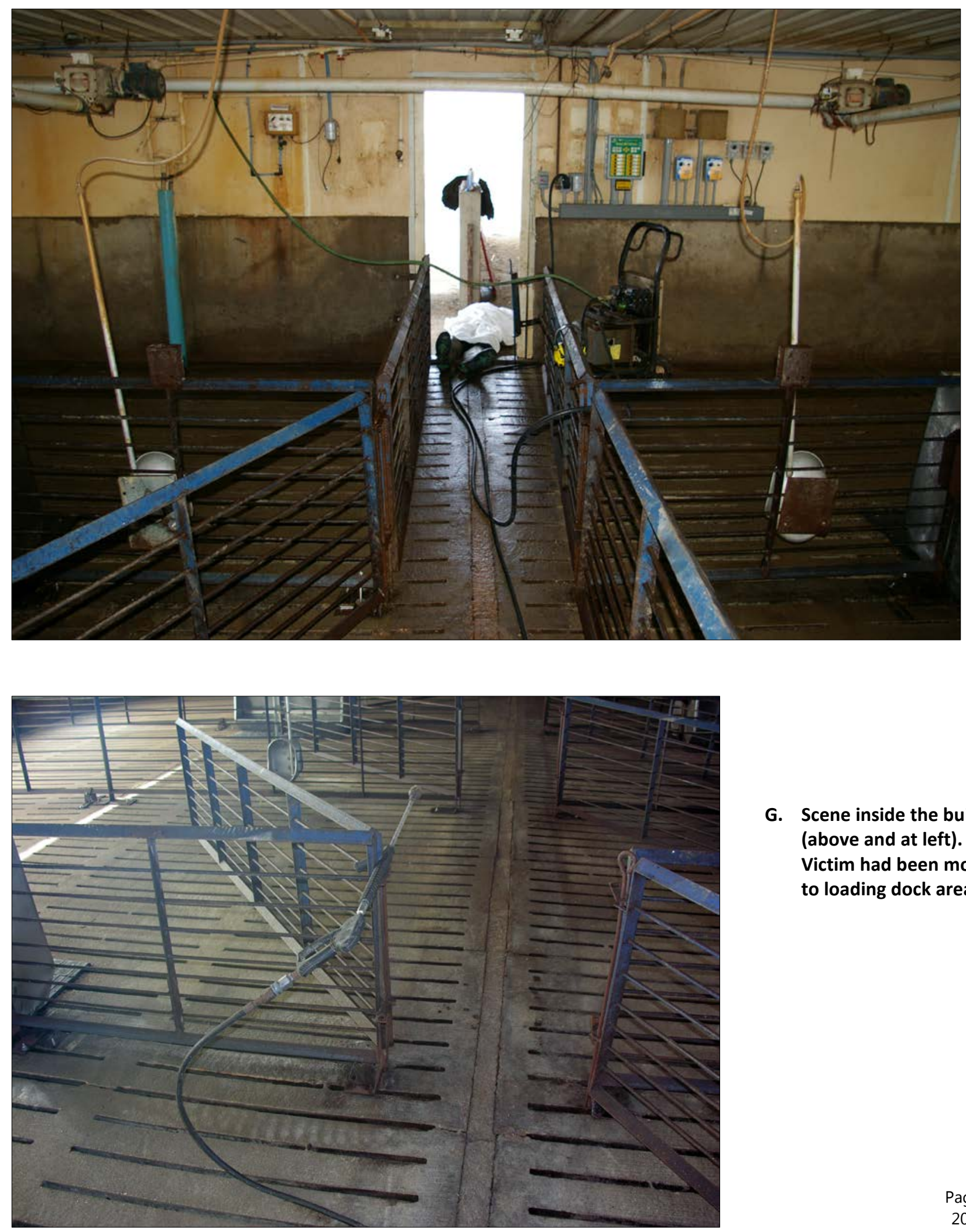

G. Scene inside the building (above and at left). Victim had been moved to loading dock area. 
As part of the IOSHA investigation, the washer was transported to the equipment dealership where it was inspected by the manufacturer's engineers and the dealer service technician four days after the fatality. The front cover of the electrical panel was opened to examine the electrical components and conductors. The engineers found:

- The bead of water-resistant sealant applied to the front access cover at the time of manufacture was missing.

- There was significant evidence of water and moisture in the electrical panel. The water inlet above the panel had had been leaking over and into the electrical panel. Water had pooled on top of the capacitors. Moisture inside the panel resulted in significant rust and corrosion on interior metal surfaces and electrical contacts (Exhibit H).

- Wiring appeared to have been shortened.

- There was heat damage to conductor insulation caused by current overload. The conductors were intact, but damage to insulation created potential for exposed conductors to touch (short circuit) or to contact the interior surface of the metal panel box, energizing the panel box and all connected metal parts (Exhibit $\mathrm{H}$ ).

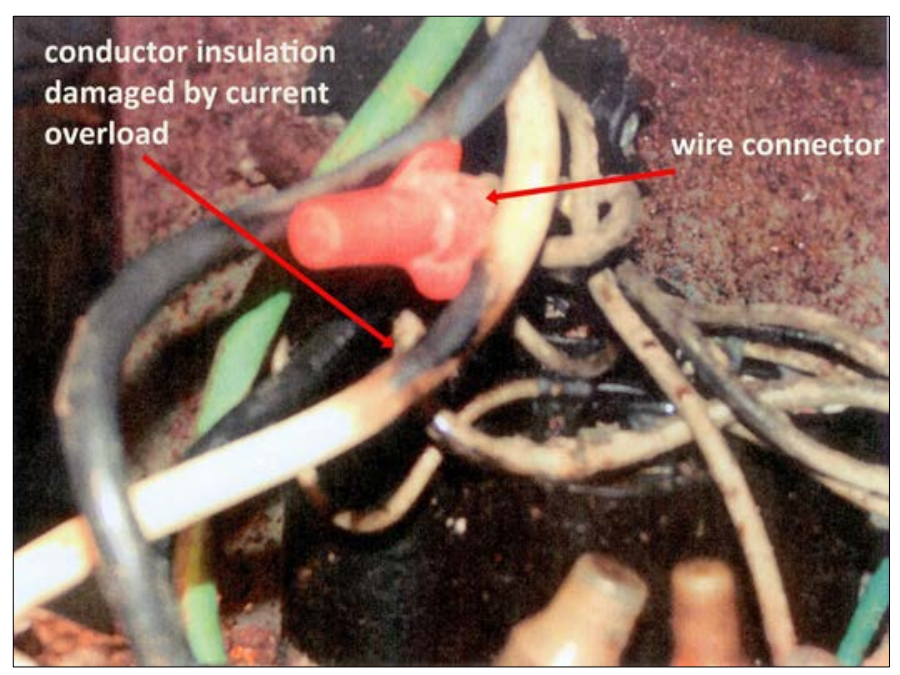

- Insulation on one capacitor post had melted, indicating current overload of the motor and wiring (Exhibit $\mathrm{H}$ ).
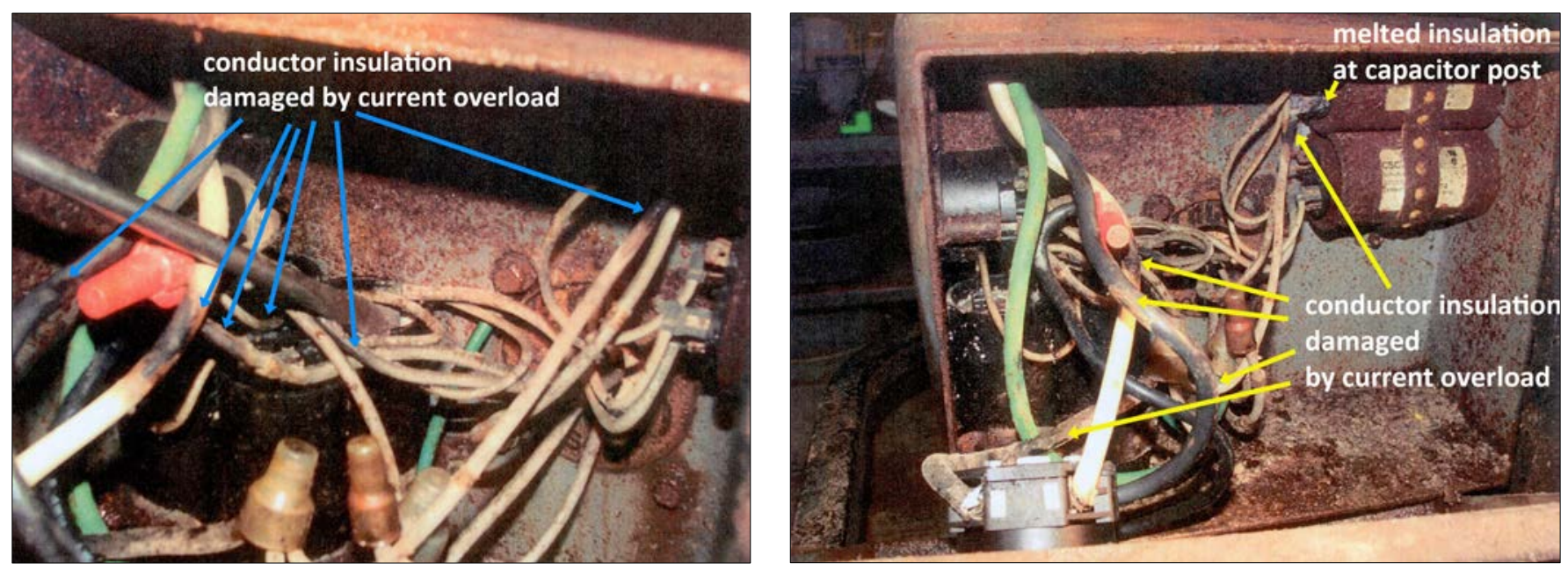

\section{H. Interior of electrical panel showing corrosion and heat damage to insulation (3 photos above)}

In addition, the IOSHA compliance officer observed there were numerous cuts and breaks in the insulation of the high pressure hose that exposed the steel reinforcement braiding (Exhibit I).

\section{Damage to insulation of high pressure hose (at right)}

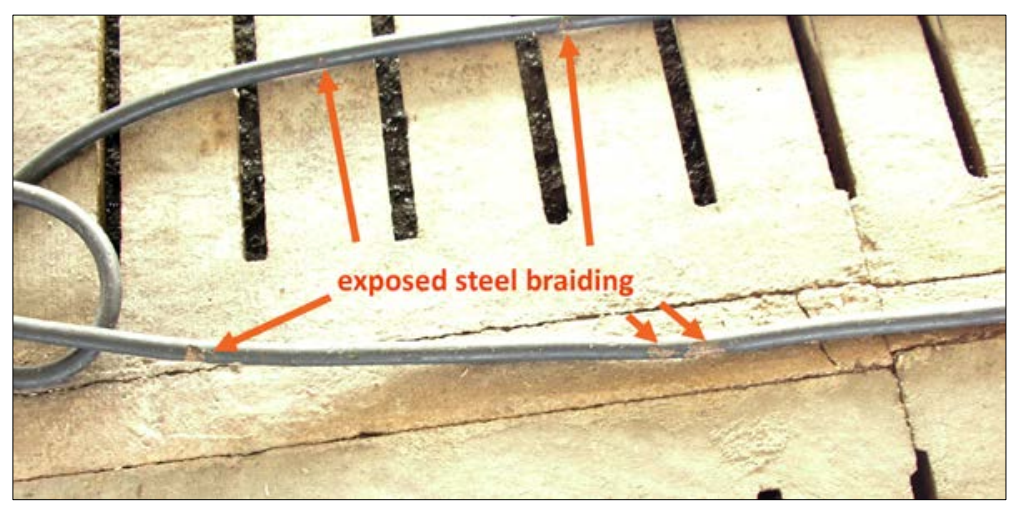


With the equipment running, power through the machine measured 230 volts and 13 amps. Power through the frame measured 33 volts and 0.02 milliamps $(\mathrm{mA}){ }^{7}$

I findings suggest it is likely that an exposed conductor in contact with the interior of the metal electrical panel - and/or water inside the electrical panel - caused a fault that energized the panel and all connected metal components of the equipment, including the frame, wand, and exposed steel braiding on the hose. The victim became part of the fault current path to ground when he simultaneously touched the energized washer and the steel gate. Wet conditions in the building - particularly the victim's wet skin and clothing - increased the severity of electric shock.

\section{Contributing factors}

Factors contributing to this fatality include

- $\quad$ use of equipment with a known history of electrical malfunction that was not maintained in safe operating condition

- use of electrical equipment without GFCI protection

- $\quad$ workers were not provided training in operation and safety hazards of electrical equipment

\section{Cause of death}

The Iowa Office of the State Medical Examiner autopsy reported the victim died of electrocution. The autopsy identified a burn on the victim's upper right anterior thigh consistent with the electric current contact site. Toxicology results were positive for caffeine.

\section{Recommendations}

\section{Use pressure washers only in applications where ground fault circuit interrupter (GFCI) protection is present and in working order.}

Ground faults occur when electricity flows along an unintended path to a grounded object or surface. This can occurr when electrical components become damaged or wet, allowing current to flow to metal parts of the equipment that are not part of its electrical circuitry. The "leakage" of current outside the circuit results in an imbalance in current flowing from from, and returning to, the circuit.

GFCIs are overcurrent protective devices ${ }^{8}$ that monitor the current flowing to electrical equipment through the hot conductor and returning from equipment through the neutral conductor. When current imbalances in the range of 0.004-0.006 amperes (4-6 mA) are detected, the GFCI opens the circuit, cutting power to the equipment.

A properly working GFCI opens the circuit at fault currents that are potentially lethal to the equipment operator who could become part of a path to ground, but that are not high enough to trip a standard breaker or fuse. The GFCI device opens the circuit in as little as $1 / 40^{\text {th }}$ second upon detection of leaking current, effectively shutting off power

\begin{tabular}{|c|l|}
\hline $\begin{array}{c}\text { Current level } \\
\text { (milliamperes) }\end{array}$ & Probable Effect on Human Body \\
\hline I mA & $\begin{array}{l}\text { Perception level. Slight tingling sensation. Still } \\
\text { dangerous under certain conditions. }\end{array}$ \\
\hline $5 \mathrm{~mA}$ & $\begin{array}{l}\text { Slight shock felt; not painful but disturbing. } \\
\text { Average individual can let go. Strong } \\
\text { involuntary reactions to shocks may lead to } \\
\text { injuries. }\end{array}$ \\
\hline $6 \mathrm{~mA}$ & Class A GFCl opens the circuit. \\
\hline $6 \mathrm{~mA}-16 \mathrm{~mA}$ & $\begin{array}{l}\text { Painful shock, begin to lose muscular control. } \\
\text { Commonly referred to as the freezing current, } \\
\text { or maximum level a person can grasp and still } \\
\text { "let-go." }\end{array}$ \\
\hline $17 \mathrm{~mA}-99 \mathrm{~mA}$ & $\begin{array}{l}\text { Extreme pain, respiratory arrest, severe } \\
\text { muscular contractions. Individual cannot let go. } \\
\text { Death is possible. }\end{array}$ \\
\hline $100 \mathrm{~mA}-2000 \mathrm{~mA}$ & Death is likely. \\
\hline$>2000 \mathrm{~mA}$ & Death is probable. \\
\hline $15,20,30$, or 50 & Common fuse or breaker opens the circuit. \\
amps & \\
\hline
\end{tabular}

\section{J. Effects of electric current}

Adapted from NIOSH Publication 98-131 \& OSHA Construction $\underline{\text { eTool }}$

\footnotetext{
7 Touch voltage and current through the frame at the time of the incident is not known; it would have been affected by the amount of water in the electrical panel and the orientation of exposed conductors in the panel prior to transporting the washer and removing the panel cover.

8 Overcurrent protective devices include fuses, circuit breakers, and GFCIs.
} 
to the equipment before current can travel through the operator's body (Exhibit J).

GFCI devices do not protect against "line-to-line" contact where a person becomes part of the circuit by touching two hot conductors, or the hot and neutral conductors, at the same time. ${ }^{9}$

\section{Standards}

The National Electric Code (NEC) requires GFCI protection for residential installations and certain nonresidential applications where electrical circuitry and equipment is used in or near wet or damp environments. High-pressure washers are among the listed applications requiring GFCI protection. ${ }^{10}$

NEC requirements for agricultural buildings include protection of permanent electrical equipment and fixtures from wet, dusty, and corrosive conditions that are present in livestock buildings and installation of GFCI protection on 125V, single-phase, 15and 20 - amp receptacles. ${ }^{11}$

OSHA requires electrical equipment that is used by employees to be listed by an approved nationally recognized testing laboratory (NRTL) such as UL. ${ }^{12}$ Factory-installed GFCI protection is one of several safety design features required of pressure washers certified to UL standard 1776, Safety Standard for High-Pressure Cleaning Machines.

In this fatal incident, neither the pressure washer nor the building electrical circuit were equipped with GFCI devices. Because livestock buildings are, by nature, damp and subject to periodic wash-down and sanitation activities, pressure washing activities should be conducted only with the following safety measures are in place:

- $\quad$ Permanently installed GFCI protection in the building's circuitry at the breaker and/or receptacles (including $240 \mathrm{~V}$ circuits with 30- and 50- amp receptacles);

- Use of UL-certified pressure washers having integrated safety design features that protect both the operator and equipment.

Professionally installed GFCI breakers or GFCI receptacles can provide ground fault protection regardless of the model pressure washer or other electrical equipment used in the building. An advantage of using GFCI breakers at the service panel is locating the device in a less corrosive environment than in the rooms where livestock are housed.

To assure that GFCI circuitry is working properly, the GFCI should be tested per manufacturer instructions before each use using the "reset" and "test" buttons (Exhibit K).

If a GFCI trips while equipment is being used, it is critical to remove the equipment from service and have a qualified technician or licensed electrician determine the cause of the fault before proceeding.

\section{K. Example of GFCI test procedure Source: PACIFICHYDROSTAR Item 69488 Electric Pressure Washer Owner's Manual \& Safety Instructions}

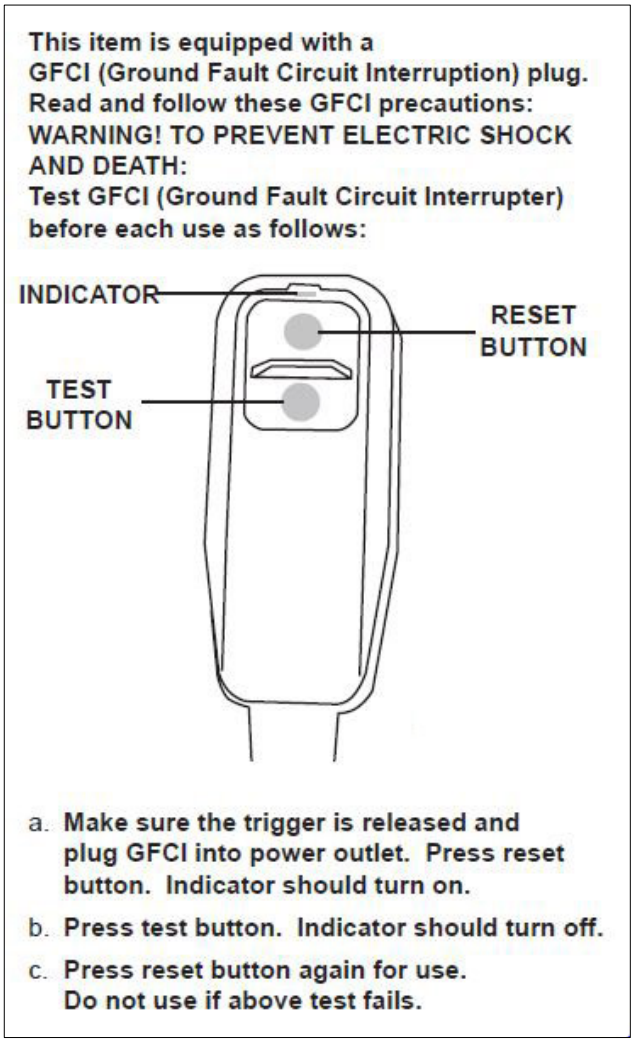

9 However, if the person also happened to be in contact with a grounded object in either of these circumstances, the GFCI would detect the imbalance in current and open the circuit.

102014 NFPA 70®: National Electrical Code Article 422.49 requires factory-installed GFCI in the attachment plug or in the power supply cord within $12^{\prime \prime}$ of the plug for a) all single phase equipment rated 250V or less; and b) all 3-phase equipment rated 208Y/120V and 60 amperes or less.

11 NEC Article 547: Agricultural Buildings

12 OSHA Standard 29 CFR 1910.399, 1910.7, and NRTL Program information 


\section{Maintain pressure washers in proper operating condition. Remove malfunctioning equipment from service until repairs have been made by qualified repair personnel.}

Pressure washers used in livestock facilities may be subject to harsh use conditions if they are stored in damp and corrosive environments or during transport from one location to another. Given the conditions of use and potential for electrical injury, it is important that they are maintained according to manufacturer specifications.

Post-incident inspection revealed that the pressure washer involved in this fatality had not been maintained in safe working order. Attempted repairs or alterations that were performed by unqualified persons failed to recognize and address potential electrical hazards - specifically, water leakage into the electrical panel, corrosion on connectors, burned insulation, and exposed conductors. Altering the orientation of the water inlet and failing to replace the seal of the electrical panel cover probably contributed to water leakage into the panel. Replacing the cordset plug after it was damaged from short circuiting a few days before the fatality did not address the internal cause of the short or remedy the shocking and power surges.

The victim and his Honduran coworker had experienced frustration at having to use the malfunctioning equipment in addition to discomfort and pain caused by its shocks. The coworker stated they had discussed the situation numerous times during the week. At lunch on the day of the fatality, the victim had expressed concerns regarding job security and believed he must continue working with the faulty equipment in order to comply with his supervisor's schedule, or risk losing his job. Although the supervisor and workers were aware that the washer was not working properly, it remained in use in order to meet schedule deadlines. If the washer had been removed from service and taken to the dealership for evaluation upon first indication of electrical malfunction, this fatality could have prevented.

Employers are responsible for assuring that electrical equipment used by their employees is maintained in proper working order and free of safety hazards. Employers should establish preventive maintenance and inspection schedules for electrical equipment based on information provided in operator manuals or by the dealer's service personnel. All leased or "on loan" equipment should come with an operator manual specific to the equipment. The manual should include prescribed inspection and maintenance schedules in addition to operating instructions.

Equipment that is leased or "on loan" (like the pressure washer in this case) should be included in employers' preventive maintenance and inspection schedules. A suggested maintenance schedule addressing pressure washer electrical safety is described below.

Daily, before each use

Employees should:

- visually inspect the plug, power cord, and receptacle for signs of physical damage;

- visually inspect the equipment electrical panel and building electrical enclosures for potential sources of water intrusion (such as breaks in water tight seals or missing covers) and evidence of corrosion or overheating;

- $\quad$ check the high pressure hose for cuts or abrasions that expose the wire braiding reinforcement;

- test the function of the GFCI (Exhibit K); if the GFCl is not working, do not use the equipment;

0 if the integrated GFCI on the pressure washer is not working, take the equipment to the manufacturer's qualified service technician;

o if a GFCI circuit-breaker or receptacle is not working, contact a licensed electrician.

Weekly, if equipment is used on a daily basis

Supervisors should:

- visually inspect for evidence of damaged, exposed, or overheated electrical components; water intrusion into electrical fixtures; and condition of the equipment grounding conductor;

0 tag and remove from service any equipment with damaged components or reported malfunction, and assure that damaged or malfunctioning equipment is repaired by a qualified technician or licensed electrician.

Quarterly (or at manufacturer's or dealer's recommendation), and in event of malfunction

Have the equipment evaluated by the dealership or manufacturer's service technician. Equipment should be checked for electrical continuity, grounding and bonding (HSE PM 29).

Annually, and in event of malfunction

Have the building's electric installation inspected by licensed electrician or engineer (HSE PM29).

Additional building considerations

Electrical receptacles and enclosures in the building should be rated for wet and corrosive environments and protected from water; covers should be in place when receptacles are not in use. 


\section{Train workers on electrical hazards associated with operating pressure washers, including risks for electric shock, routine inspection and maintenance procedures, and proper use of equipment. Verbal training and written materials should be provided in workers' primary language.}

Agricultural workers are among four industry groups with higher rates of electrical fatalities than the rate for private industry overall (ESFI). Most electrical deaths among agricultural workers result from contact with overhead power lines or contact with electric current of machine, tool, appliance, or light fixture. ${ }^{13}$ A steady decline in the annual number of US electrical fatalities is attributed, in part, to better and increased worker training, but contact with electric current continues to rank sixth or seventh in cause of occupational fatalities overall (ESFI), and fifth among Hispanic worker fatalities (Sanders-Smith).

Before being required to use pressure washers, employees should be trained verbally, provided a demonstration of proper operation and inspection procedures, and given the opportunity to read and understand the operator's manual for the specific equipment they will be using. Employee training should cover the following points:

a) How to identify hazards posing risk of electric shock, including

- improperly grounded equipment;

- equipment not protected by properly working GFCI;

- damaged or altered electrical components (e.g., power cords, plugs, exposed conductors, substituted electrical components, signs of overheating);

- use of electrical equipment or extension cords in damp and wet environments;

- warning signs that indicate electrical malfunction, such as: GFCIs or breakers tripping while equipment is in use, short circuits, electrical shocks, arcing to metal surfaces, equipment power surges, shut-down, or overheating; these signs indicate the source of the electrical problem must be investigated and resolved before continuing work;

- $\quad$ evidence of / potential for water leaking into the electrical panel;

- increased severity of electric shock in wet or damp conditions.

b) Daily or pre-use inspection protocols to be performed prior to operating equipment (see Recommendation 2 above).

c) Protocols for follow up in the event that an unsafe condition or defect is identified during inspection or operation:

- tag the equipment and remove it from service;

- notify the supervisor;

- do not use the equipment unless it has been evaluated and repaired by a qualified technician or licensed electrician.

d) Safe operation of pressure washers based on recommendations provided in the operator's manual and manufacturer's training materials, including

- care when moving the equipment to avoid damage or strain to electrical enclosures and components;

- care when moving and positioning the high pressure hose and power cable to avoid catching or dragging them on sharp surfaces that could cut, scrape, or puncture them;

- $\quad$ protection of electrical connections from standing water or spray;

- using washers only with GFCI-protected, dedicated circuits (i.e., no other loads on the circuit) having appropriate ampacity for the equipment rating;

- routing the power cord so it will not 1) cause strain at the plug or electrical box, 2) become a trip hazard, or 3) require use of an extension cord;

- GFCI test procedures;

- instruction to never modify or alter the equipment.

All verbal and written training should be provided to employees in their primary language. Employers should obtain and provide bilingual equipment operator manuals, safety and operating decals, and training materials such as videos or other booklets for employees whose primary language is not English. Translators or other bilingual employees should assist, if needed, to assure that employees understand training instructions and written materials. Employees should be provided opportunities to ask questions about equipment they operate and be urged to communicate any concerns or hazardous conditions that are noted with the assurance that identified hazards will be remediated.

13 ESFI at http://www.esfi.org/index.cfm/page/Summary/pid/11740 
NAICS sector:

Keywords:

\section{Agriculture}

Hispanic worker, farm worker, electrocution, shock, pressure washer, livestock, ground fault, ground fault circuit interrupter, GFCI

\section{Resources}

- Do you use a steam/water pressure cleaner? You could be in for a shock! Health and Safety Executive (HSE). 2002. INDG68 (rev). http://www.hse.gov.uk/pubns/indg68.pdf

- How Electrical Current Affects the Human Body. OSHA Construction eTool. https://www.osha.gov/SLTC/etools/construction/electrical_incidents/eleccurrent.html

- $\quad$ Maintaining portable electrical equipment. HSE. 2013.

PDF available at: http://www.hse.gov.uk/pubns/books/hsg107.htm

\section{Other cases}

- $\quad$ North Carolina Department of Labor. Sykes, S. Deadly Mistakes: Farm worker electrocuted while using pressure washer. North Carolina Labor Ledger. September/October 2006.

http://www.nclabor.com/news/Deadly\%20Info/06DeadlySeptOct.pdf

- $\quad$ Paris A. The case of the shocking power washer. Electrical Construction \& Maintenance. August 2010. http://ecmweb.com/bonding-amp-grounding/case-shocking-power-washer

- $\quad$ OSHA. Accident: 14521132 - Electric shock - ground fault in high-pressure washer

- $\quad$ OSHA. Accident: 200271195 - Employee is electrocuted while using power washer

- Health and Safety Executive (HSE). Worker received shock whilst using a pressure water washing machine. http://www.hse.gov.uk/electricity/maintenance/washingmachine.htm 


\section{References}

Apartment News Publications. Pressure Washer Warning.

http://www.aptcontractors.com/pressure-washer-warning

Centers for Disease Control and Prevention (CDC). 2006. Pressure Washer Safety Fact Sheet.

http://emergency.cdc.gov/disasters/pdf/pressurewashersafety.pdf

Consumer Product Safety Commission (CSPC). 2010. GFCI Fact Sheet. Publication 099.

http://www.cpsc.gov//PageFiles/118853/099.pdf

Electrical Safety Foundation International (ESFI). Workplace Safety Injury and Fatality Statistics Summary.

http://www.esfi.org/index.cfm/page/Summary/pid/11740

ESFI. Electrical Safety Then and Now - 20 Years of Electrical Injury Data Shows Substantial Electrical Safety

Improvement. http://esfi.org/index.cfm/page/Electrical-Safety-Then-and-Now/cdid/12394/pid/10272

HSE. 2007. Electrical risks from steam/water pressure cleaners. Guidance Note PM29.

http://www.hse.gov.uk/pubns/priced/pm29.pdf

National Fire Protection Association (NFPA). 2014 NFPA 70: National Electrical Code ${ }^{\circ}$.

Available at http://www.nfpa.org/codes-and-standards

NFPA. 2012 NFPA 70E: Standard for Electrical Safety in the Workplace ${ }^{\circledR}$.

Available at http://www.nfpa.org/codes-and-standards

National Institute for Occupational Safety and Health (NIOSH). 1998. Worker Deaths by Electrocution; A Summary of NIOSH Surveillance and Investigative Findings. DHHS Publication 1998-131.

http://www.cdc.gov/niosh/docs/98-131/pdfs/98-131.pdf

OSHA Construction eTool: How Electric current Affects the Human Body.

https://www.osha.gov/SLTC/etools/construction/electrical incidents/eleccurrent.html

PACIFICHYDROSTAR ${ }^{\circledR} . \mathbf{1 6 5 0}$ PSI electric pressure washer Owner's Manual \& Safety Instructions. Item 69488.

http://manuals.harborfreight.com/manuals/69000-69999/69488.pdf

Sanders-Smith S. 2007. Hispanic Worker Safety - Understanding culture improves training and prevents fatalities.

Professional Safety.

http://www.asse.org/professionalsafety/pastissues/052/02/030207AS.pdf

Weidner G. 2005. Modern GFCIs. Cleaner Times.

http://www.cleanertimes.com/pdfdocs/2005CTMag/Safety-Modern\%20GFCIs\%202005-12.pdf

WORKSAFE BC. 2008. High Pressure Washing - Safety Work Practices.

http://www.worksafebc.com/publications/health and safety/by topic/assets/pdf/bk123.pdf

\section{Acknowledgements}

Iowa FACE thanks the Iowa Division of Labor and the Iowa Division of Criminal Investigation for their assistance and the use of photographs included in this report, and Mr. Robert Olson, Jr. (Master Electrician, retired) for technical assistance and review.

\section{Investigator information}

This report was prepared by Stephanie Leonard and reviewed by Renée Anthony. ${ }^{14}$

\footnotetext{
${ }^{14}$ This publication was supported by Cooperative Agreement Number 5 U60OH008460 from CDC-NIOSH, through an award to the lowa Department of Public Health Occupational Health \& Safety Surveillance Program and a sub-award to the University of Iowa FACE program. Its contents are solely the responsibility of the authors and do not necessarily represent the official views of CDC-NIOSH or IDPH.
} 


\title{
Fatality Assessment and Control Evaluation (FACE) Program
}

The National Institute for Occupational Safety and Health (NIOSH), an institute within the Centers for Disease Control and Prevention (CDC), is the federal agency responsible for conducting research and making recommendations for the prevention of work-related injury and illness. In 1982, NIOSH initiated the Fatality Assessment and Control Evaluation (FACE) Program. FACE examines the circumstances of targeted causes of traumatic occupational fatalities so that safety professionals, researchers, employers, trainers, and workers can learn from these incidents. The primary goal of these investigations is to make recommendations to prevent similar occurrences. The Iowa FACE Program is one of nine state-based programs funded by NIOSH that conducts surveillance of occupational fatalities and conducts in-depth investigations of targeted lowa cases. FACE investigations are intended to reduce or prevent occupational deaths and are completely separate from the rulemaking, enforcement and inspection activities of any other federal or state agency. Under the FACE program, investigators interview persons with knowledge of the incident and review available records to develop a description of the conditions and circumstances leading to the deaths in order to provide a context for the FACE Program's recommendations. The FACE summary of these conditions and circumstances in its reports is not intended as a legal statement of facts. This summary, as well as the conclusions and recommendations made by Iowa FACE, should not be used for the purpose of litigation or the adjudication of any claim. For further information, visit the Iowa FACE Program website at http://www.public-health.uiowa.edu/face/ (phone 800-513-0998), and the NIOSH FACE Program website at www.cdc.gov/niosh/face/ (phone 800-CDC-INFO / 800-232-4643).

The Iowa FACE team at the University of Iowa includes Stephanie Leonard, Program Director/Field Investigator, and Renée Anthony, Co-Director. Additional expertise is provided from Iowa FACE partners John Kraemer, Director, Forensic Operations at Iowa Office of the State Medical Examiner; and Stuart Schmitz, Principal Investigator and Kathy Leinenkugel, Co-Principal Investigator/Program Manager, both at the Iowa Department of Public Health.

For additional information regarding this report or the Iowa FACE Program contact:

\author{
Iowa FACE Program \\ The University of Iowa \\ Department of Occupational and Environmental Health \\ UI Research Park, 240 IREH \\ Iowa City, IA 52242-5000
}

Toll free: (800) 513-0998

Fax: (319) 335-4085

www.public-health.uiowa.edu/face

E-mail: cph-face@uiowa.edu 